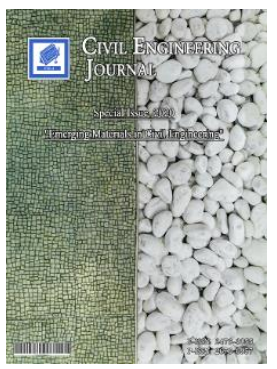

\title{
Torsional Strengthening of Reinforced Concrete Beams with Externally-Bonded Fibre Reinforced Polymer: An Energy Absorption Evaluation
}

\author{
Mahir M. Hason a , Ammar N. Hanoon ${ }^{\mathrm{b}}$, Ahmed W. Al Zand ${ }^{\mathrm{c} *}$, \\ Ali A. Abdulhameed ${ }^{\text {b }}$, Ali O. Al-Sulttani ${ }^{\text {d }}$ \\ ${ }^{a}$ Disaster Management Centre, Ministry of Science and Technology, Iraq. \\ ${ }^{b}$ Department of Reconstruction and Projects, University of Baghdad, Baghdad, Iraq. \\ ${ }^{c}$ Department of Civil Engineering, Universiti Kebangsaan Malaysia, Selangor, Malaysia. \\ ${ }^{d}$ Department of Water Resources Engineering, College of Engineering, University of Baghdad, Baghdad, Iraq.
}

Received 02 September 2020; Accepted 29 November 2020

\begin{abstract}
The impacts of numerous important factors on the Energy Absorption (EA) of torsional Reinforced Concrete (RC) beams strengthened with external FRP is the main purpose and innovation of the current research. A total of 81 datasets were collected from previous studies, focused on the investigation of EA behaviour. The impact of nine different parameters on the Torsional EA of RC-beams was examined and evaluated, namely the concrete compressive strength $\left(f^{\prime} c\right)$, steel yield strength $(f y)$, FRP thickness $\left(t_{F R P}\right)$, width-to-depth of the beam section $(b / h)$, horizontal $\left(\rho_{\mathrm{h}}\right)$ and vertical $\left(\rho_{\mathrm{v}}\right)$ steel ratio, angle of twist $(\theta u)$, ultimate torque $(T u)$, and FRP ultimate strength $(f y-F R P)$. For the evaluation of the energy absorption capacity at different levels, Response Surface Methodology (RSM) was implemented in this study. Also, to fit the measured results, Quadratic and Line models were created. The results show that the RSM technique is a highly significant tool that can be applied not only to energy absorption-related problems examined in this research, but also to other engineering problems. An agreement is observed between Pareto and standardized charts with the literature showing that the EA capacity of the torsional FRP-RC beams is mostly affected by the concrete compressive strength, followed by the vertical reinforcement ratio. The newly suggested model in this article exhibits a satisfactory correlation co-efficient (R), of about $80 \%$, with an adequate level of accuracy. The obtained results also reveal that the EA acts as a safety index for the FRP-strengthened RC beams exposed to torsional loadings to avoid sudden structural damage.
\end{abstract}

Keywords: Energy Absorption; Reinforced Concrete Beams; Torsional Strengthening; FRP, Response Surface Method (RSM).

\section{Introduction}

Generally, in buildings, bridges, and other such structures, Reinforced Concrete (RC) members are exposed to a sequence of significant actions such as flexural, shear, and torsional moment, which may result in structural failure [13]. In comparison with shear and flexural impacts, torsion is typically taken into consideration as a secondary effect. As a result, the available literature consists of limited research into the torsional behaviour of RC structural members [4]. Note that in cases like curved girders in bridges, spandrels, and curved beams in buildings, the torsional effects

* Corresponding author: ahmedzand@ukm.edu.my

http://dx.doi.org/10.28991/cej-2020-SP(EMCE)-07

(C) 2020 by the authors. Licensee C.E.J, Tehran, Iran. This article is an open access article distributed under the terms and conditions of the Creative Commons Attribution (CC-BY) license (http://creativecommons.org/licenses/by/4.0/). 
play an important role. In addition, seismic movements have the potential to exert serious torsional damage to structures that have an irregular geometry [5].

Various techniques exist in literature to strengthen RC beams that are exposed to torsional moment [7]. One of these techniques is adding outer reinforcement to the member [6]. For this purpose, fiber-reinforced polymer (FRP) composites are applied to RC structures, which has been proven to have higher effectiveness in comparison with conventional methods of reinforcement, such as steel jackets. FRP has some advantages such as high flexibility, being a corrosion-resistant material, a high strength-to-weight ratio, and low thermal conductivity [7-9]. FRP-RC beams have been broadly employed as energy absorption designs, because they tend to deform higher than traditional RC beams, specifically due to higher energy absorption [10]. Based on the results of many experiments carried out in different studies it is determined that externally-bonded FRP composites are capable of strengthening RC beams in torsion [11-13].

When working with structural designs, maintaining the safety of structures and buildings that are exposed to various loads needs more than just investigating their energy absorption, which indicates their structural integrity. This factor helps to preserve the system unity at the time of exposure to any unanticipated physical load. Multiple complex processes involve absorbing the energy of RC elements. In fracture mechanics, cracks initiation, cracks propagation, and elastic-plastic deformation are indexes for energy absorption process. The energy absorption capacity also represents the level of flexural performance after concrete cracking occurs. Note that various factors have the potential to impact the values of energy absorption, including steel reinforcement ratios (horizontal and vertical) and concrete compressive strength, especially with torsional loading impact. None of the previous or current studies have argued or debated the major and minor effects of those parameters together on the EA of the torsional FRP-RC beams. The laboratory confirmation revealed that FRP material and high concrete grade can be employed, as a powerful and valuable procedure relative to conventional methods, to develop the torsional strength of RC beams [14, 15].

In order to develop the energy absorption behavior of the torsion RC beam, a large number of schemes were suggested over the years. Compared with the conventional RC beam, the FRP-RC beam has been noted to be more constant by many researchers [16]. The literature contains only a few studies focusing on the upgrading of torsional members by FRP materials. These investigations explain the magnificent role of the FRP technique on RC beams under oblique loads; however, the energy absorption performance of the FRP-RC beams under torsion loads was not satisfying. Therefore, it is essential to investigate the absorbed energy of the various beams exposed to excessive torsional forces, retrofitted by different thickness of FRP composites and also to determine the most critical factors that affect the performance of the mentioned EA of those beams. Additionally, the present research attempts to investigate the factors that have an effect on energy absorption; the reason behind this focus is the increasing importance of examining the EA capacity and to express which factors have the maximum and minimum influences on the torsional EA performance of FRP-RC beams.

Historically, numerous methods have been improvised to label various areas of knowledge, which have offered several preliminary designs among which the most popular ones are Taguchi designs, the central composite design (CCD), design of experiments (DOE), and Box-Behnken design (BBD). These methods have been utilised individually or in combination. Recently, a number of researchers have applied RSM to effectively establishing a mathematical relationship between the input and output parameters in a way to optimize them. DOE makes use of the response surface methodology (RSM) (see Figure 1) and defines a suitable model, necessary to create a relationship between the independent factors and the dependent response [17]. Thus, it is essential to suggest an effective method to estimate the EA of the structure members (i.e., FRP-RC beams exposed to torsional load). In this study, the optimization techniques are used mainly for the purpose of achieving values for the selected parameters of a torsional EA model in a way that makes it possible to maximize and minimize the objective functions that are exposed to constraints.

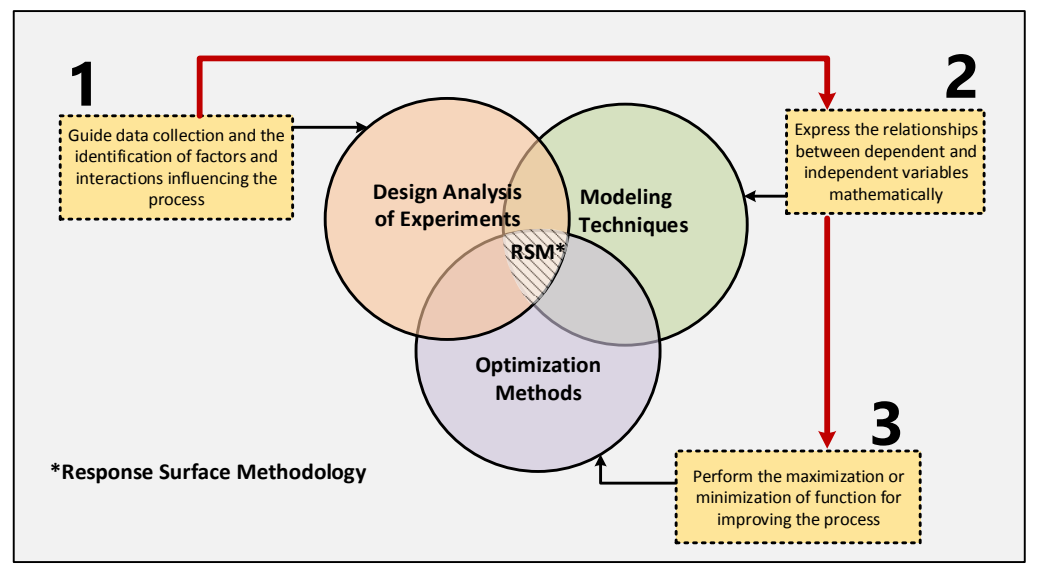

Figure 1. Response Surface Methodology (RSM) [18] 
Arm to arm with DOE methods, the analysis of variance (ANOVA) and other terms examinations according to tstatistics are generally employed for the aim of discovering the significance of the examined input variables and also explaining the most important effects of the cooperation of control factors upon the response variables in a mathematical way. This typically describes the critical-to-quality properties of ultimate results like the dissipated energy, torsional load tensile strength, etc. [18].

Various researchers have examined the option of upgrading the RC beams externally bonded with FRP sheets subjected to shearing, bending, or both. However, there are still many questions concerning the energy absorption of the RC beams strengthened in torsion with the use of FRP sheets. None of the studies, as per the knowledge of the researchers of this paper, have evaluated the impact of multiple parameters like the compressive strength $\left(f^{\prime} c\right)$, steel yield strength $(f y)$, FRP thickness $\left(t_{F R P}\right)$, width-to-depth of the beam section $(b / h)$, horizontal $\left(\rho_{\mathrm{h}}\right)$ and vertical $\left(\rho_{\mathrm{v}}\right)$ steel ratio, angle of twist $(\theta u)$, ultimate torque $(T u)$, and FRP ultimate strength $(f y-F R P)$, on the torsional EA of FRP-RC beam. Thus, the objective of the present study is to investigate the factors affecting the capacity of absorbing energy in torsional FRP-RC beams, with various angles of a twist. This paper is considered to be the first innovative study conducted to evaluate the influences of these nine parameters on the energy dissipation of the RC-beams reinforced with FRP material. The torsional scientific literature was collected and reviewed in order to gather a consistent test database from 81 torsional tests carried out on the RC beams strengthened with FRP. RSM, DOE, and ANOVA methods were used in analysing, comparing, and formulating the outputs. The interaction between the mixture contents was modelled utilizing Central Composite Design (CCD). The parameters with high and low impacts were defined and arranged. Besides, a new model has been proposed, which can be applied for similar datasets and can also be applied to future studies to estimate the torsional energy absorption, depending on the evaluated test factors.

\section{Significance of the Investigation}

Many researchers have focused on examining how RC structures behave under different loads; however, there is still a key challenge, i.e., the calculation of the energy absorption of the structures retrofitted with FRP-strengthening, especially for the RC concrete beams exposed to torsional loads. Thus, this study attempts to focus on the evaluation of the parameters that impact the way energy is absorbed by the torsional FRP-strengthened RC beams. In addition, an innovative formulation is introduced by means of the DOE software. It is worth mentioning that the current paper represents the first effort to evaluate and debate the degree of effect of the critical parameters on the energy absorption of the torsional FRP-RC beams. This might affect future researches in terms of choosing major and minor factors in the torsional experiment of RC beams enhanced with FRP sheets. Besides, fabricating a new formula to predict the torsional EA of FRP-RC beams has certainly contributed to the forecast studies before conducting an individual one.

\section{Research Methodology}

\subsection{Database Description}

All pertinent literature was comprehensively reviewed and the results of 81 experimented RC beams retrofitted with different FRP laminate configurations were gathered (see Table 1). Eight inputs were set, namely, concrete compressive strength $\left(f_{c}^{\prime}\right)$, width to depth of beam section $(b / h)$, steel yield strength $\left(f_{y}\right)$, horizontal $\left(\rho_{h}\right)$ to vertical $\left(\rho_{v}\right)$ steel ratio, FRP ultimate strength $\left(f_{y-F R P}\right)$, angle of twist $\left(\theta_{u}\right)$, FRP thickness $\left(t_{F R P}\right)$, and ultimate torque $\left(T_{u}\right)$. The output was set to be the energy absorption values of the FRP-strengthened RC beams. Figure 2 displays the sample distribution and the variables applied to the measurement of energy absorption. Also, the specimens applied to measure the energy absorption capacity are statistically described in Table 2.

Table 1. The naming of beam specimens utilized in the database

\begin{tabular}{lc}
\hline \multicolumn{1}{c}{ Sample ID } & Reference \\
\hline C1, C2, C3, C4, C5, C6, G1, G2 & {$[19]$} \\
A90W4, A90S4, A0L4, A0L3, B0L4/90S4, B90U3-Anch, C90U3 & {$[20]$} \\
B2, B3, B4, B5 & {$[21]$} \\
FS050D2 & {$[12,13,22,23]$} \\
CFE, CFE2, CJE, CFS, CJS, GFE, GFE2, GJE, GFS, GJS & {$[11]$} \\
Ra-F(1), Ra-F(2), Ra-Fs150(2), Rb-F(1), Rb-Fs200(1), Rb-Fs300(1) & {$[24]$} \\
ACS1, ACUJ-anc., ACW1, ACW2, BCS1, BCUJ-anc., BCW1, BCW2, CCW1, CCW2 & {$[25]$} \\
CW1(1), CW1(2), CW1(3), CW2, CUJ-anc, CS1, CS2 & {$[26]$} \\
WR1, WR2 & {$[27]$} \\
CFB1, CFB2, CFB3, CFB4, CFB5, CFB6, GFB1, GFB2, GFB3, GFB4, GFB5, GFB6 & {$[28]$} \\
BR2, BR3, BR4, BR5 & {$[29]$} \\
FT, FL, 100S100, CO\&100S100, DS, CO\&DS & {$[30]$} \\
CS1, CUJ-anc, CW1, CW2 & {$[31]$} \\
\hline
\end{tabular}



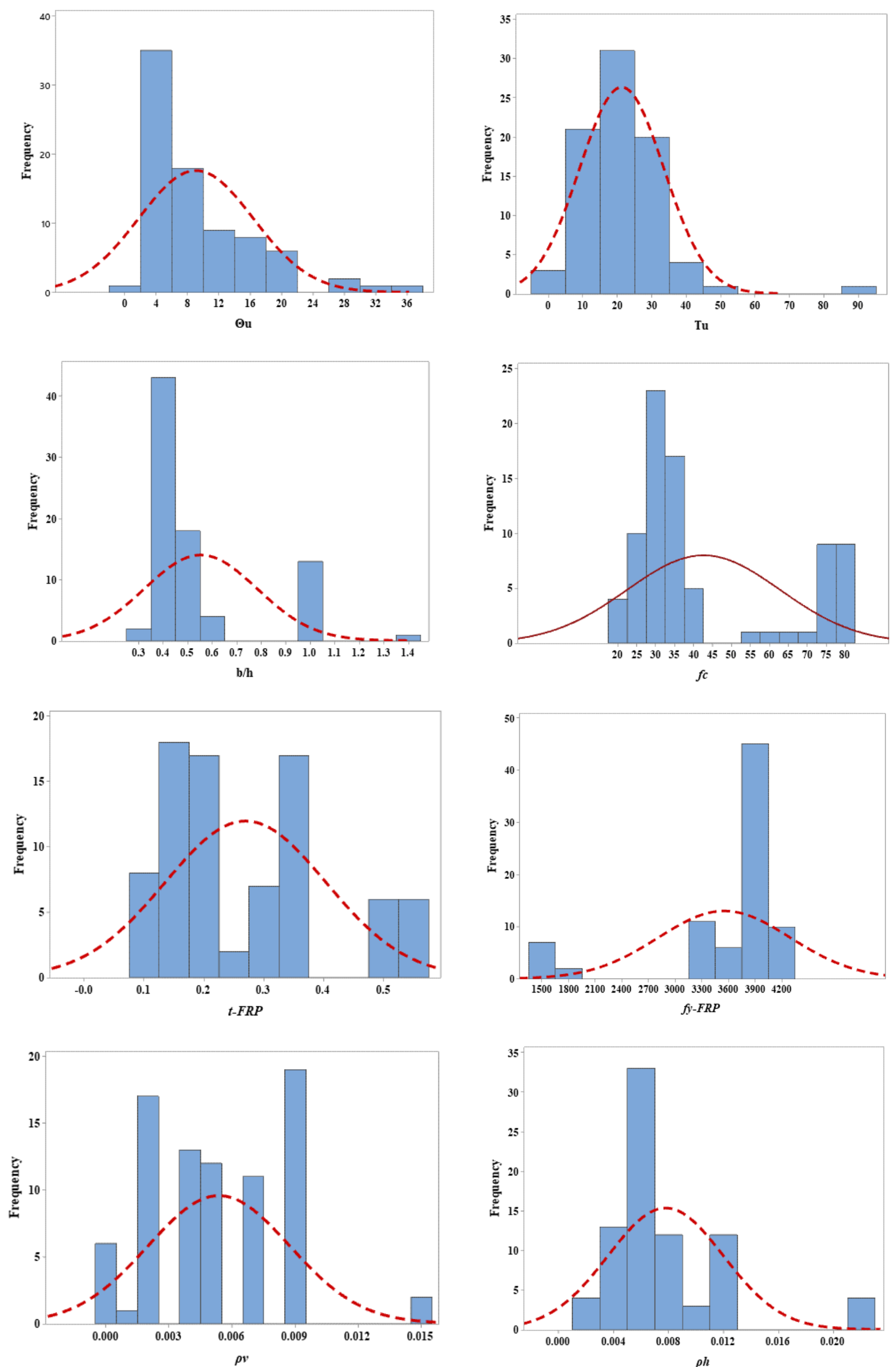


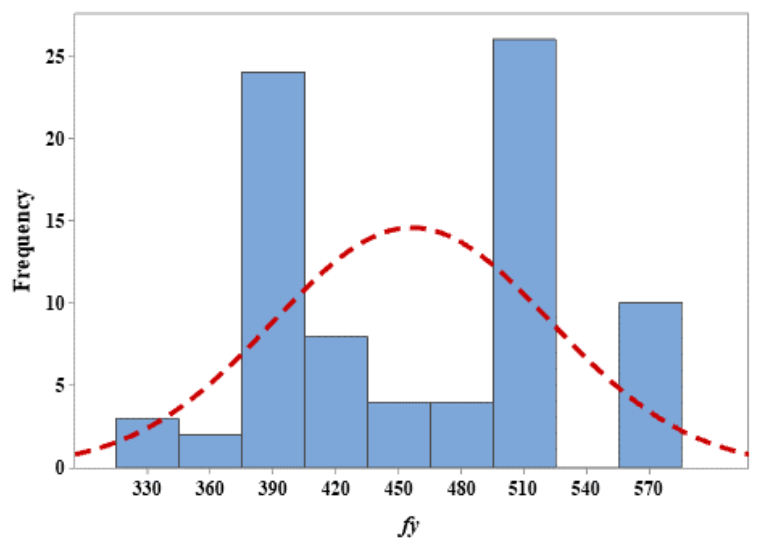

Figure 2. Histograms of independent input variables

Table 2. Descriptive statistics of the variables used in the database

\begin{tabular}{cccccccccc}
\hline & $\begin{array}{c}\boldsymbol{\Theta}_{\boldsymbol{u}} \\
(\boldsymbol{d e g r e e})\end{array}$ & $\begin{array}{c}\boldsymbol{T}_{\boldsymbol{u}} \\
(\boldsymbol{k N . m})\end{array}$ & $\boldsymbol{b} / \boldsymbol{h}$ & $\begin{array}{c}\boldsymbol{f}_{\boldsymbol{c}}^{\prime} \\
(\mathbf{M P a})\end{array}$ & $\begin{array}{c}\boldsymbol{t}_{\boldsymbol{F R P}} \\
(\mathbf{m m})\end{array}$ & $\begin{array}{c}\boldsymbol{f}_{\boldsymbol{y}-\boldsymbol{F R P}} \\
(\mathbf{M P a})\end{array}$ & $\boldsymbol{\rho}_{v}$ & $\begin{array}{c}\boldsymbol{\rho}_{\boldsymbol{h}} \\
(\mathbf{M P a})\end{array}$ & $\begin{array}{c}\boldsymbol{f}_{\boldsymbol{y}} \\
(\mathbf{M P a}\end{array}$ \\
\hline Mean & 9.08 & 21.21 & 0.55 & 42.60 & 0.27 & 3552.35 & 0.01 & 0.01 & 456.22 \\
Standard Deviation (SD) & 7.33 & 12.26 & 0.23 & 20.20 & 0.13 & 745.78 & 0.00 & 0.00 & 66.53 \\
Coefficient of variation (CoV) & $80.76 \%$ & $57.78 \%$ & $41.72 \%$ & $47.43 \%$ & $50.03 \%$ & $20.99 \%$ & $62.96 \%$ & $54.02 \%$ & $14.58 \%$ \\
Minimum & 1.57 & 3.02 & 0.30 & 20.00 & 0.11 & 1520.00 & 0.00 & 0.00 & 320.00 \\
Maximum & 36.53 & 93.80 & 1.43 & 80.56 & 0.53 & 4300.00 & 0.01 & 0.02 & 575.00 \\
Count & 81 & 81 & 81 & 81 & 81 & 81 & 81 & 81 & 81 \\
\hline
\end{tabular}

\subsection{Energy Absorption Capacity}

In steel-reinforced beams with clear plastic deformation of steel at yield, deformation methods can be employed for the purpose of computing ductility. Deformations may appear in the form of curvatures, deflections, or strains. Generally, in FRP-strengthened beams, it is very complicated to determine a clear yield point, since the conventional definition of ductility is not clearly applicable [32]. Moreover, considering the ductility of structural members is not sufficient to preserve their safety when subjected to exceptional loads as well as environmental loads. On the other hand, energy absorption can be held as a measure of structural system integrity when subjected to unexpected loadings [9]. It has been well documented that one way to estimate the loading capability of a structure is taking into consideration the concept of energy. The main challenge is finding a way to predict the capacity of energy absorption (EA) in a structure [33].

Obviously, different complicated operations are involved in the EA of reinforced concrete members, e.g., cracks initiation and propagation, elastic and plastic deformations in the concept of fracture mechanics [34, 35]. In addition, there are many documented studies carried out on the EA of RC beams, but there seems to be an inadequacy of research into the EA of FRP-strengthened RC beams with torque effect. In the case of FRP-strengthened RC beams, the EA capacity can be evaluated through measuring the area under their torque vs the angle of twist results (see Figure 3).

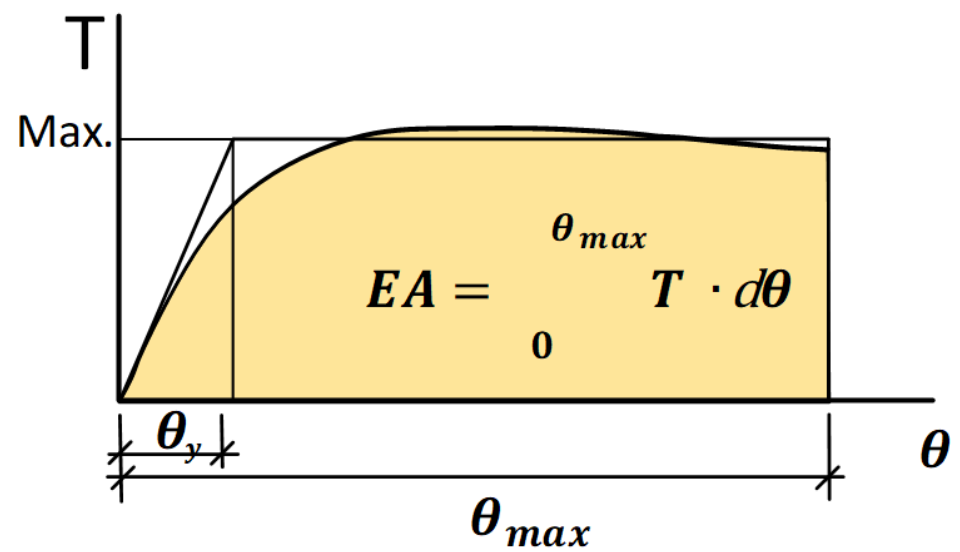

Figure 3. Definition of energy absorption factor by the torque-angle of twist curve 


\subsection{Statistical Model Design}

Two steps are involved in the process of creating a new model: 1) deriving the final model on the basis of the available datasets, and 2) carrying out parametric research based on physical features of the problem in hand and engineering principles. The former is done with the help of the Response Surface Methodology (RSM), and the latter needs to be conducted by an engineer who is aware of the problem in hand. Therefore, a parametric analysis is needed to be done. The main objective of the present paper is evaluating the effects of individual parameters on the process of energy absorption.

RSM is widely known as a statistical/mathematical technique that can be effectively employed to model and analyze the problems with the use of the second-order polynomial or quadratic models as shown in Figure 4 [36, 37]. RSM reveals how different parameters are responded in a way to determine the optimum value of the output. In fact, the central composite design (CCD) is a certain approach to the response surface methodology. CCD is of a high degree of flexibility in cases where the initial upper and lower bounds of the favourite parameters are exceeded. This approach can yield the optimum values of the parameters appearing to be out of the range that has been initially preset. The present research aims to examine the factors that have an effect on the energy absorption capacity. To study the interaction between the design parameters, a statistical approach, namely the design of the experiment (DOE) method was used through the implementation of the central composite design approach of RSM. In addition, this approach was adopted to minimize the total number of tests [38].

Factorial designs are simply implemented for the purpose of identifying the optimal combination of the factors and also the interaction between the factors; this cannot be accomplished by means of the conventional optimization processes. In addition, these designs can generate mathematical models. A second-order polynomial model (Equation 1) for the RSM was normally executed for the aim of predicting the impacts of different factors upon a response based on the datasets gathered from available literature, as follows:

$y=\beta_{o}+\sum_{i=1}^{k} \beta_{i i} x_{i}^{2}+\sum_{1 \leq i \leq j}^{k} \beta_{i j} x_{i} x_{j}+\varepsilon$

Where $\mathrm{y}$ stands for the estimated response, $x_{i}$ and $x_{j}$ denote the coded variables, $\beta_{o}$ signifies the constant, $\beta_{i}$ represents the linear coefficient, $\beta_{i i}$ denotes the quadratic coefficient, $\beta_{i j}$ signifies the interactive coefficient, and $\varepsilon$ is a random error.

The key factors that can depict the energy absorption capacity were selected based on the literature review and trial study [9, 39]. Consequently, Equation 2 was considered to be the formulation of energy absorption capacity:

$E A=f\left(b / h, f_{c}^{\prime}, \rho_{v}, \rho_{h}, t_{F R P}, f_{F R P}, f_{y}, T_{u}\right.$, and $\left.\theta_{u}\right)$

Where $E A$ the energy absorption capacity, $b / h$ the width to depth ratio, $f_{c}^{\prime}$ the concrete compressive strength, $\rho_{v}$ the vertical steel ratio, $\rho_{h}$ the horizontal steel ratio, $t_{F R P}$ FRP thickness, $f_{F R P}$ FRP ultimate strength, $f_{y}$ the steel yield strength, $T_{u}$ the ultimate torque, and $\theta_{u}$ the angle of twist.

\section{Results and Discussion}

\subsection{Parametric Analyses}

As mentioned earlier, the primary objective of the present paper is examining how individual parameters affect energy absorption. Figure 5 illustrates that energy absorption is a function of the concrete compressive strength capacity $\left(f_{c}^{\prime}\right)$ with varied parameters $\left(b / h, \rho_{v}, \rho_{h}, t_{-F R P}, f_{y-F R P}, f_{y}, T_{u}\right.$, and $\left.\theta_{u}\right)$. Through this plot, the increase of the FRP thickness, torque, angle of twist, vertical steel ratio of depth to width of a certain level results in an increase in the energy absorption capacity. On the other hand, when EA reduces, growth takes place in the steel yield strength, FRP ultimate strength, and horizontal steel ratio. As a result, the outcome obtained from the parametric analyses can be used as a guide in the evaluation of EA by choosing appropriate parameters.

It can be observed from the contour graph of Figure 5 that the maximum EA is reached when the compressive strength ranges from $70 \mathrm{MPa}$ to $80 \mathrm{MPa}$, with an angle of twist of 25-35 degrees, ultimate torque of 40-50 kN.m and 85-110 kN, FRP thickness of 0.33-0.4 mm, vertical steel ratio of 0.014, horizontal steel ratio of 0.005-0.0125, and steel yield strength of 470-500 MPa. Meanwhile, the minimum EA capacity decreases to the least value when the compressive strength is between 20-32 MPa with an angle of twist lower than 7 degrees, ultimate torque is lower than $20 \mathrm{kN} . \mathrm{m}$ and higher than $120 \mathrm{kN} . \mathrm{m}$, b/h ratio is lower than 0.6 , FRP thickness is lower than $0.27 \mathrm{~mm}$, FRP ultimate strength is higher than 3500 , vertical steel ratio is $0.004-0.008$, horizontal steel ratio is higher than 0.02 , and steel yield strength is higher than $500 \mathrm{MPa}$. 


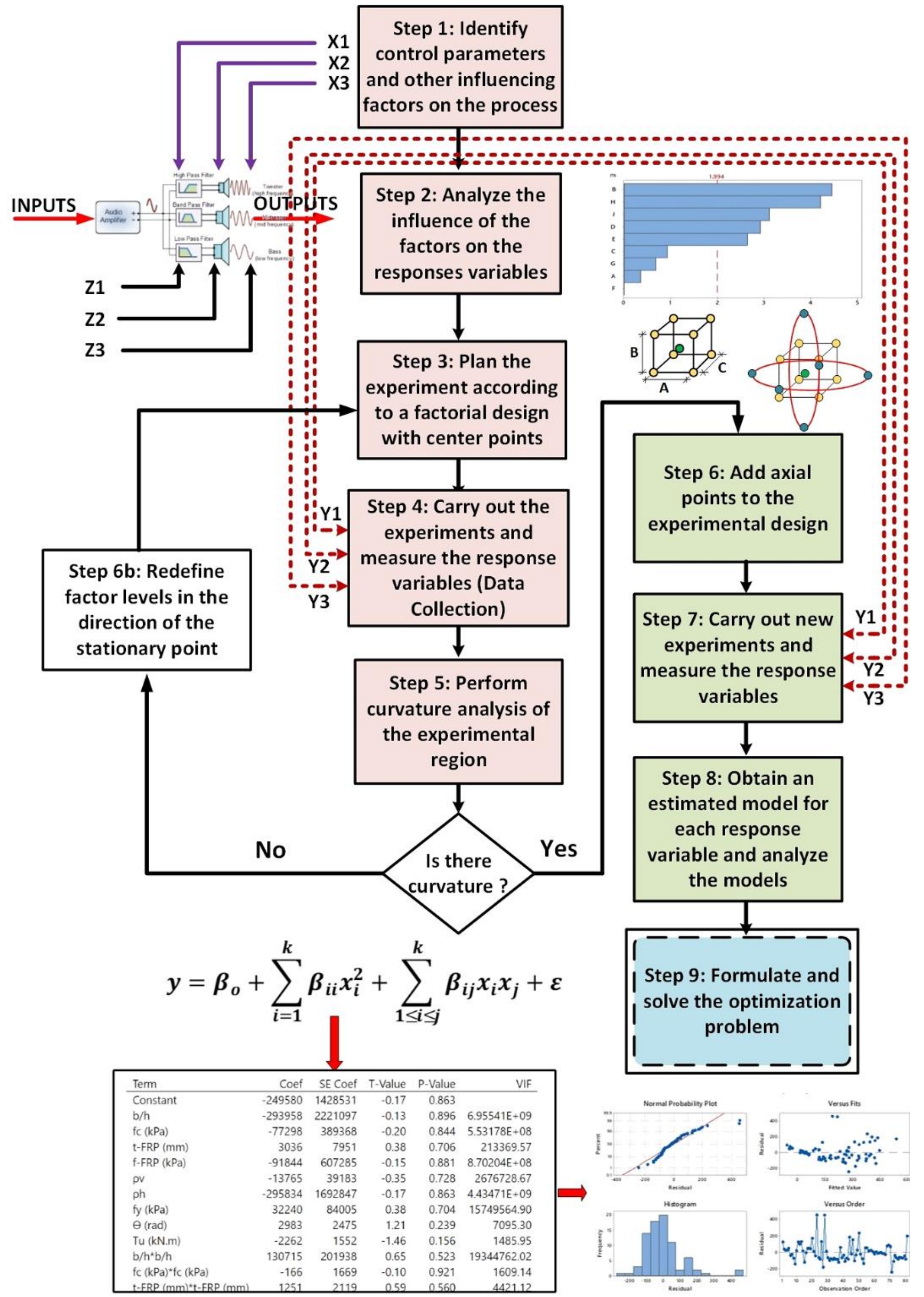

Figure 4. Flow chart of RSM adopted in this study 


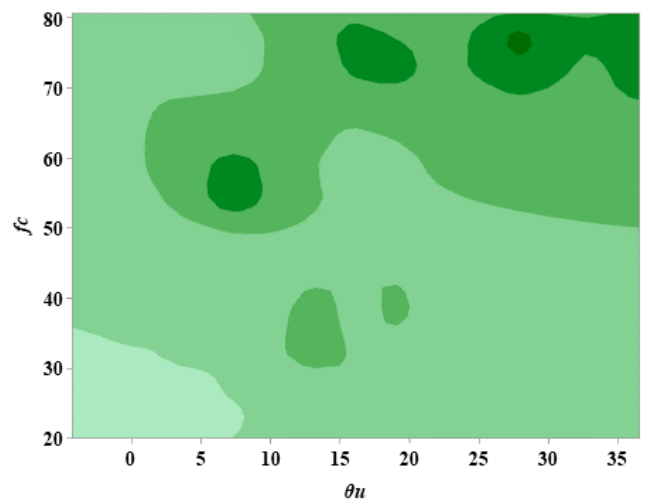

(a) Contour plot of EA vs $f_{c}^{\prime}$ and $\Theta_{u}$

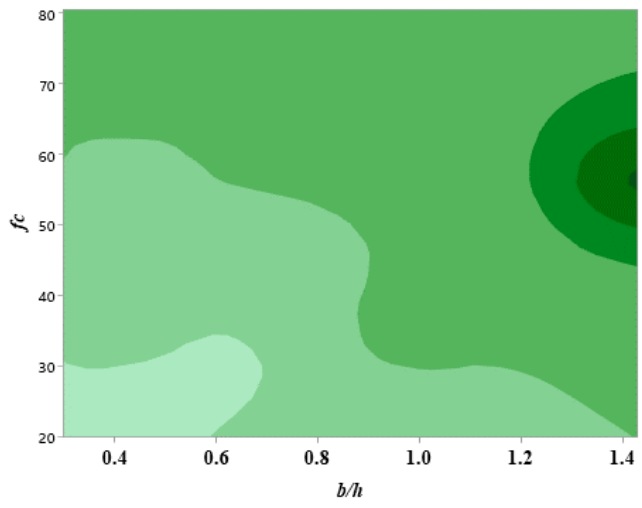

(c) Contour plot of EA vs $f_{c}^{\prime}$ and $b / h$

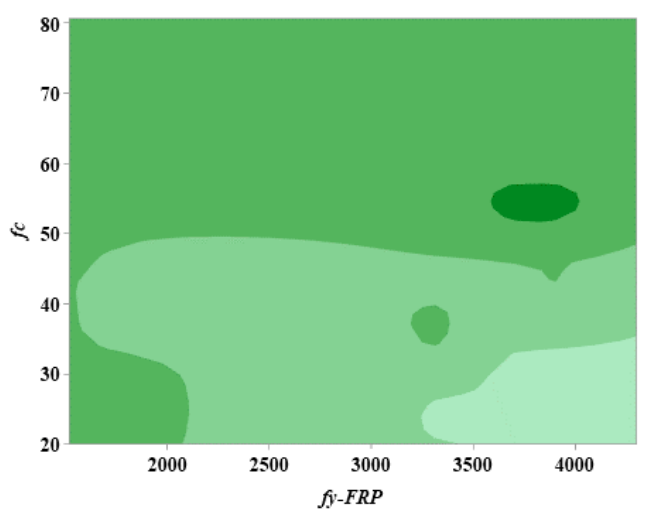

(e) Contour plot of EA vs $f_{c}^{\prime}$ and $f y_{-F R P}$

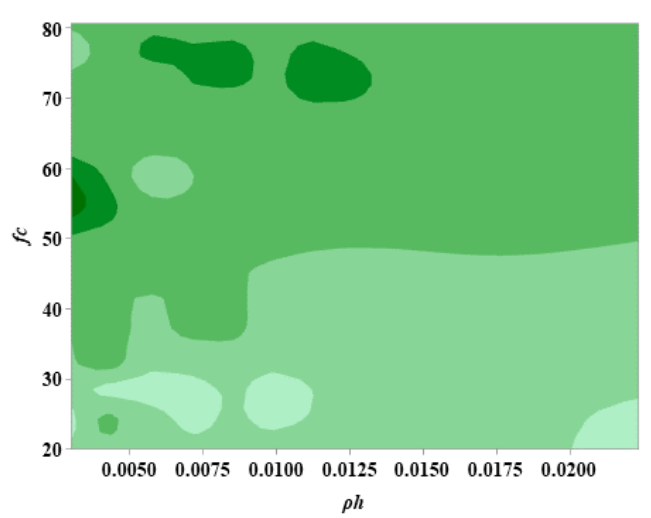

(g) Contour plot of EA vs $f_{c}^{\prime}$ and $\rho_{h}$

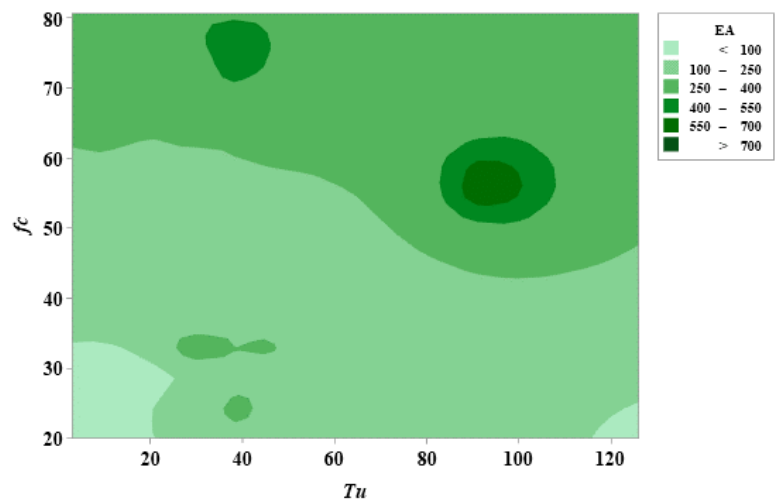

(b) Contour plot of EA vs $f_{c}^{\prime}$ and $T u$

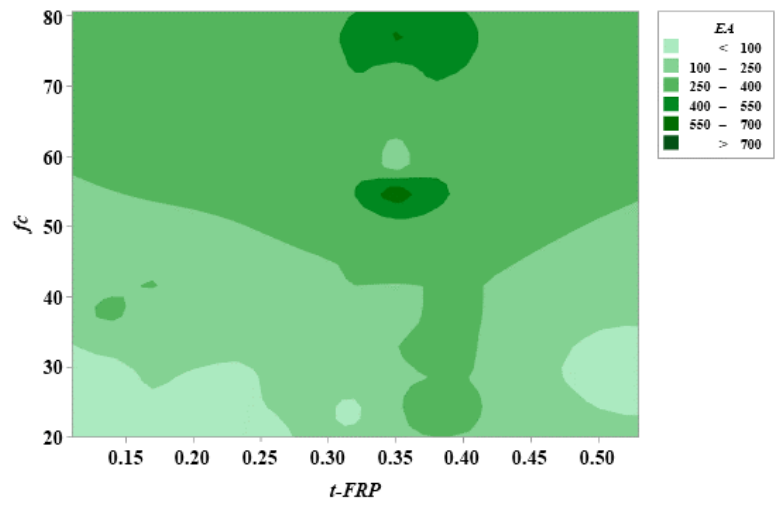

(d) Contour plot of EA vs $f_{c}^{\prime}$ and t-FRP
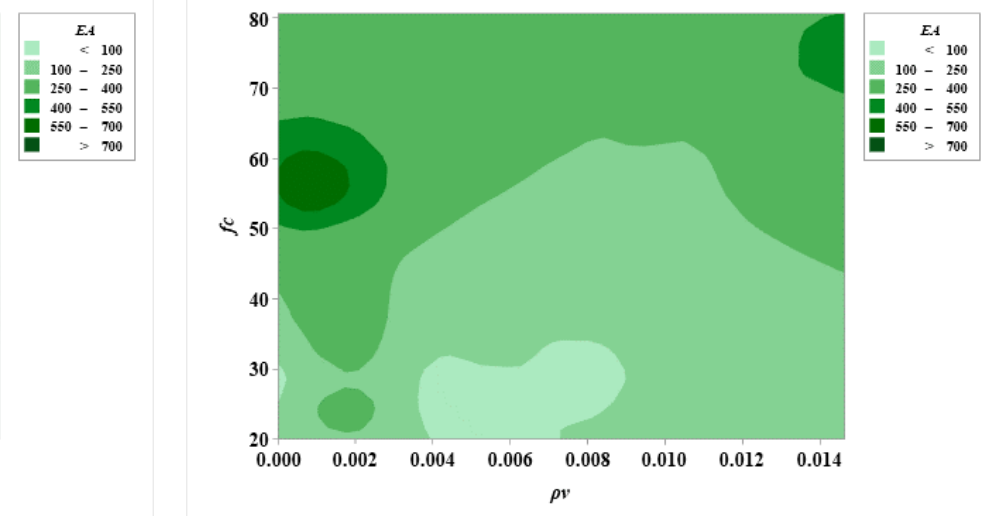

(f) Contour plot of EA vs $f_{c}^{\prime}$ and $\rho_{v}$
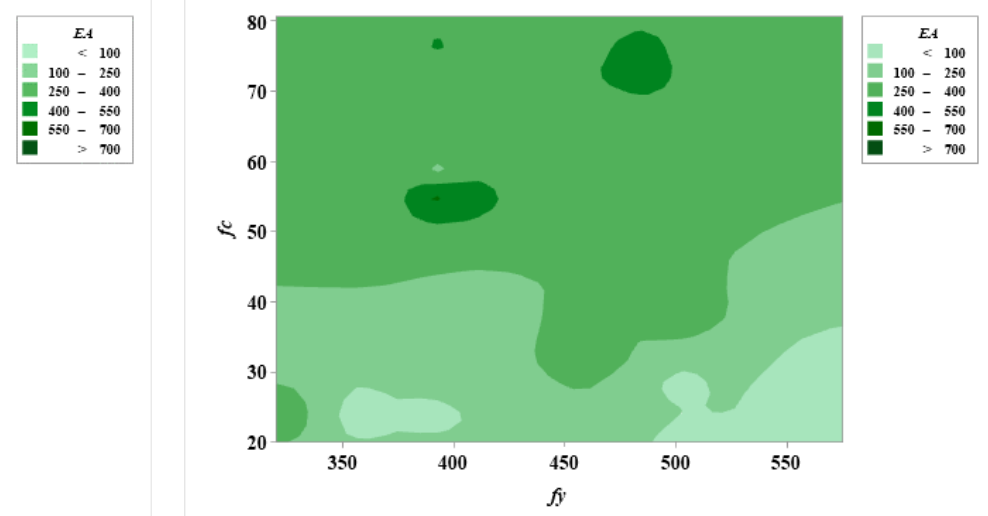

(h) Contour plot of EA vs $f_{c}^{\prime}$ and $f y$

Figure 5. Energy absorption of the parametric analysis vs. compressive strength for FRP-RC beam subjected to torsion loading 


\subsection{The Interaction Effect of Processing Parameters}

All results obtained from this research were further evaluated for the interaction plot of the capacity of energy absorption, as shown in Figure 6. It is obviously apparent that, in some cases, the difference in response between the levels of one factor is not the same at all levels of the other factor. Thus, interaction is formed among the factors. Each intersection shows that a remarkable interaction exists among the variables. Interaction plots in Figure 7 (a-d) specify the interaction between $f_{c}^{\prime}$ and $t_{F R P}, \rho_{v}, \theta_{u}$, and $T_{u}$, respectively, which is substantial due to the non-parallel lines. Consequently, those factors have positive impacts on the response (EA) based on the levels of $f^{\prime}{ }_{c}$. Whereas, a slight interaction was indicated for $f_{y-F R P}$ and $f_{y}$, as depicted in Figure 7 (e-f). By contrast, poor interaction between the $\rho_{h}$ and $b / h$ led to a weak influence on EA, as presented in Figure 7 (g-h).

According to the factorial plot in Figure 6, the best-fitted mean of energy absorption (EA) can be designed based on the interaction between the variables, i.e., high fitted mean of EA of the torsional RC beam enhanced with FRP material is obtained when the dimension ratio is equal to 1.4 with compressive strength of $80.56 \mathrm{MPa}$, FRP thickness is $0.53 \mathrm{~mm}$, FRP yield strength is $1520 \mathrm{MPa}$, vertical steel ratio is at the minimum, longitudinal steel ratio is 0.022 , yield steel is $320 \mathrm{MPa}$, angle of twist is at $1.57^{\circ}$ and ultimate torque is at $3.02 \mathrm{kN}$.m. Accordingly, the designer of torsional FRP-RC beams has the opportunity to choose the values of the independent parameters before proceeding with the experimental study. It can be seen from Figure 7 that the high mean value of EA is also obtained from the individual interactions between the variables, for example, when the $f^{\prime} c$ of about $56.4 \mathrm{MPa}$ interacted with the $t_{F R P}$, $\rho_{v}, \theta_{u}, T_{u}, f_{y F R P}, f_{y}, \rho_{h}$ and $b / h$ of about $0.35 \mathrm{~mm}$, minimum ratio, $7.9^{\circ}, 93.8 \mathrm{kN} . \mathrm{m}, 3800 \mathrm{MPa}, 398 \mathrm{MPa}, \mathrm{minimum}$ ratio and 1.43 respectively. On the other hand, the low EA is achieved when the $f^{\prime} c$ of about $30 \mathrm{MPa}$ interacted with the $t_{F R P}, \rho_{v}, \theta_{u}, T_{u}, f_{y F R P}, f_{y}, \rho_{h}$ and $b / h$ of about $0.13 \mathrm{~mm}, 0.01,0.00^{\circ}, 14.4 \mathrm{kN} . \mathrm{m}, 4300 \mathrm{MPa}, 575 \mathrm{MPa}, 0.01$ and 0.6 consecutively. This is acceptable since the increase in EA is related to the increase in the compressive strength of the concrete grade.

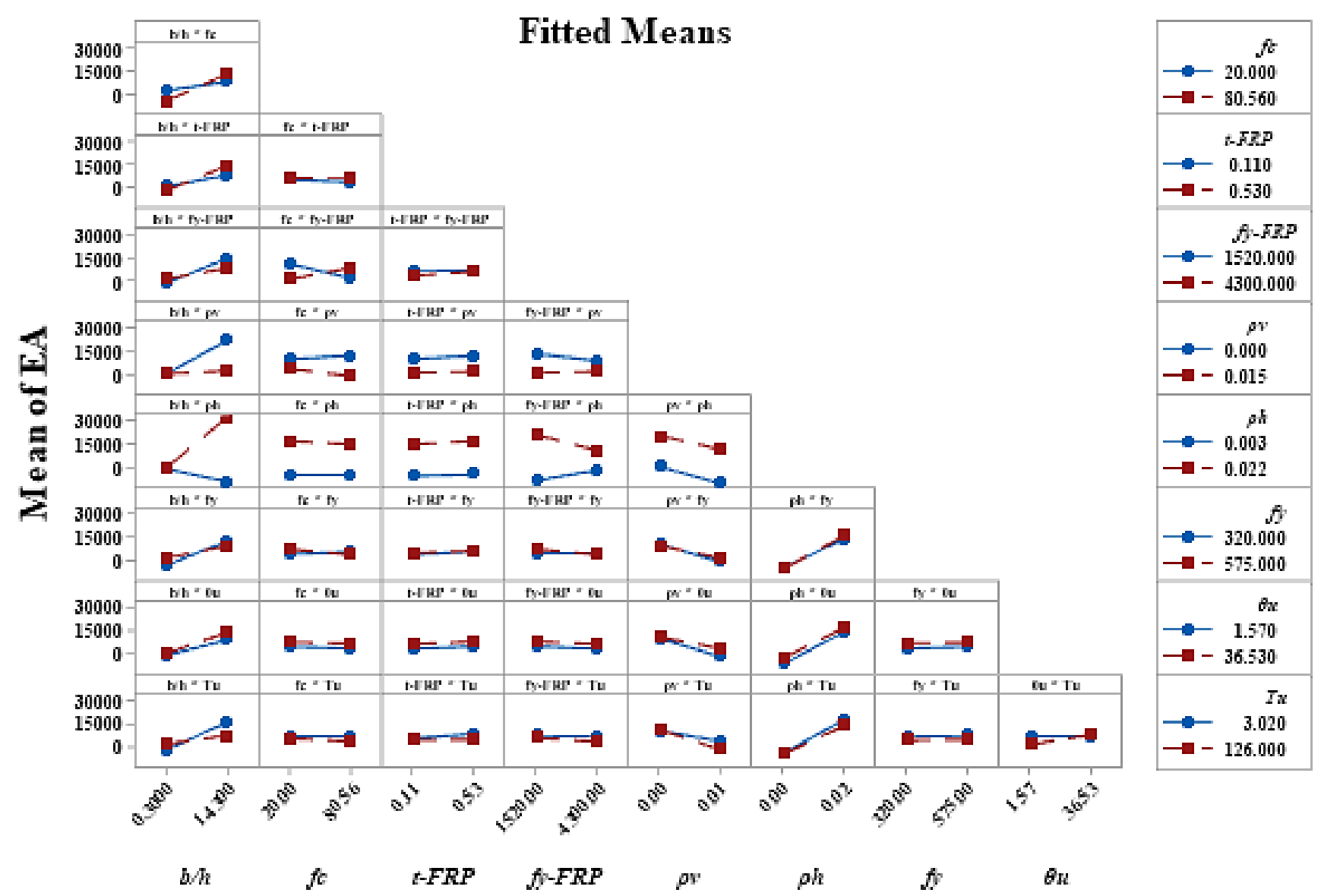

Figure 6. Interaction plot (fitted means) for energy absorption capacity 


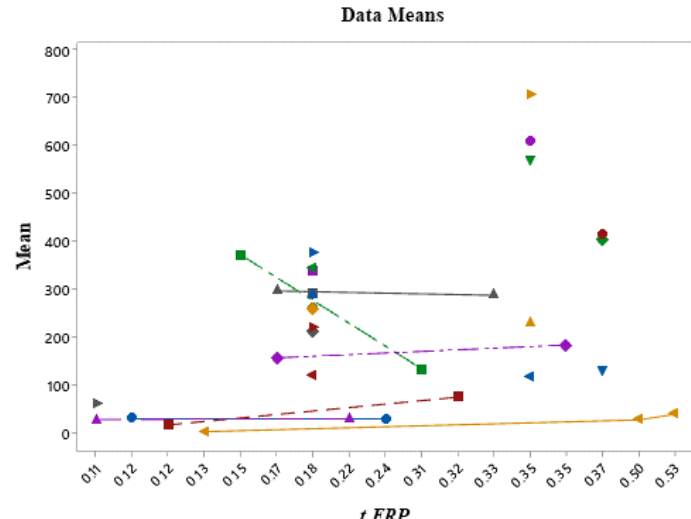

a) FRP thickness

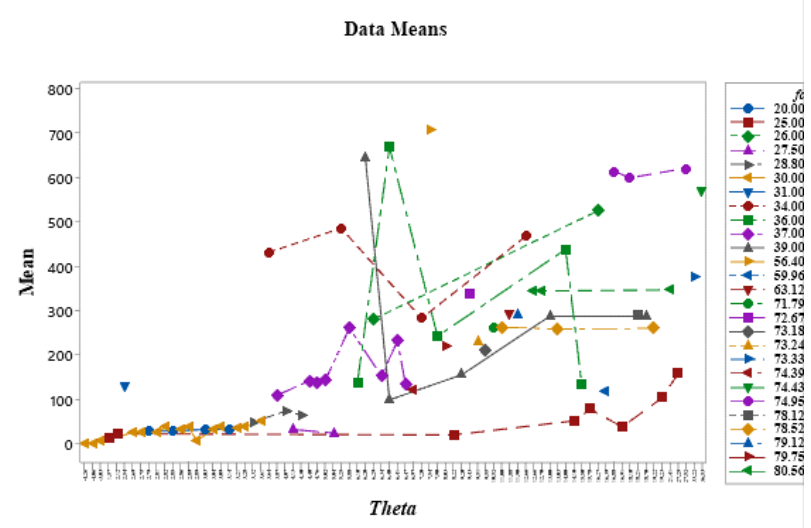

c) Angle of twist

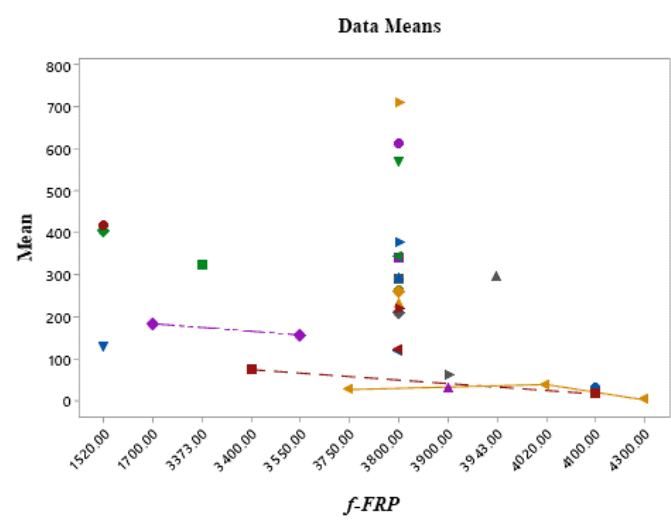

e) Ultimate strength of FRP

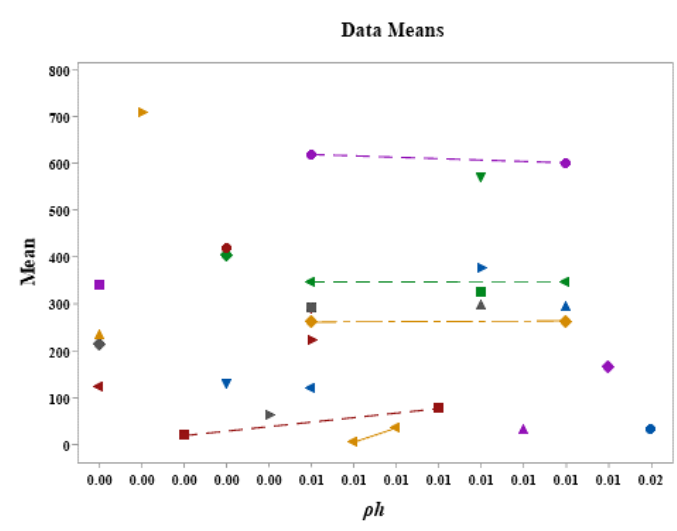

g) Horizontal steel ratio

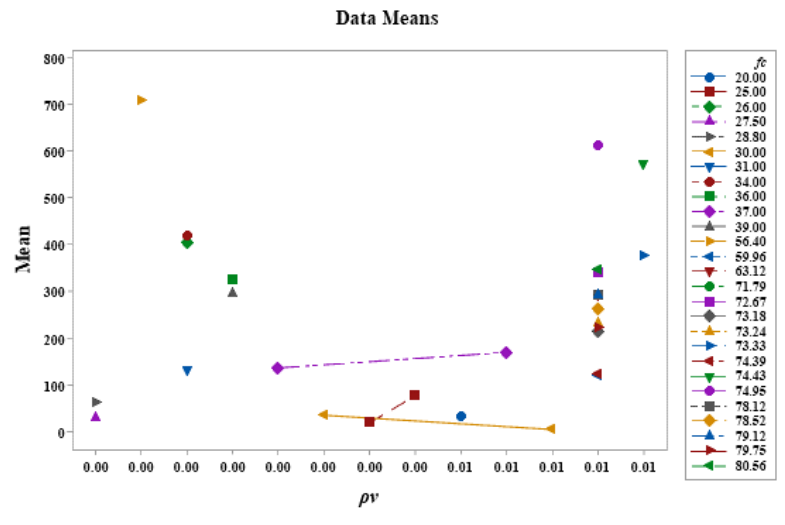

b) Vertical steel ratio

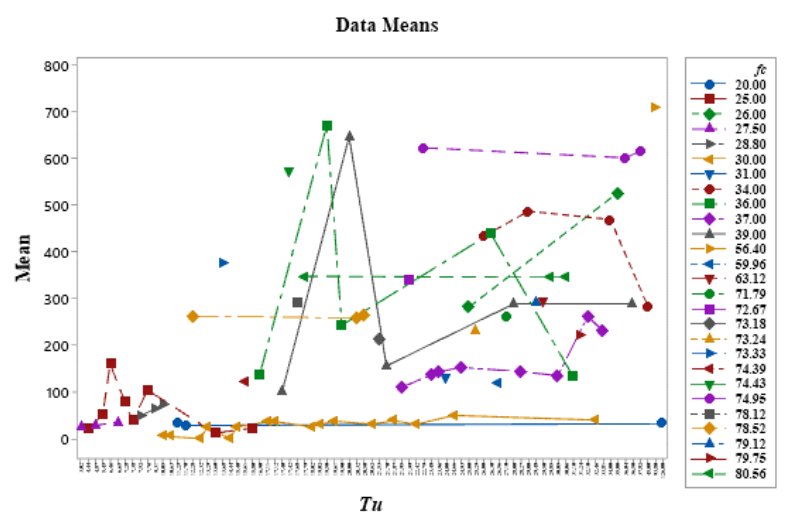

d) Ultimate torque

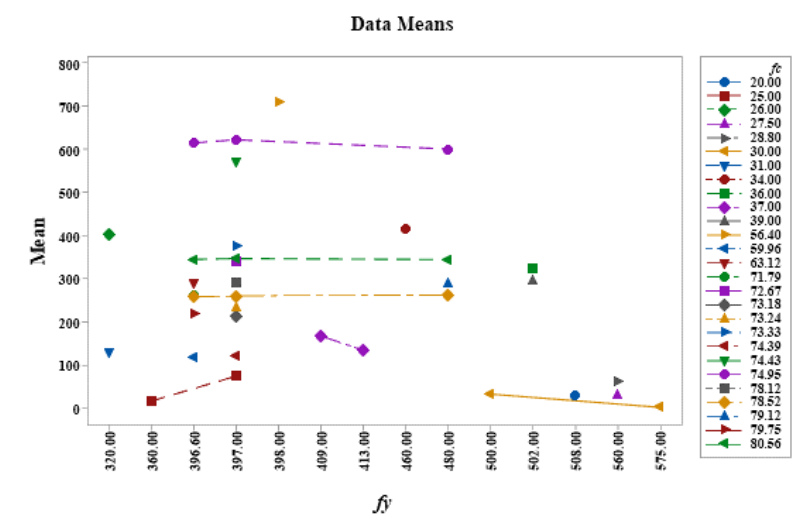

f) Yield strength of steel reinforcement

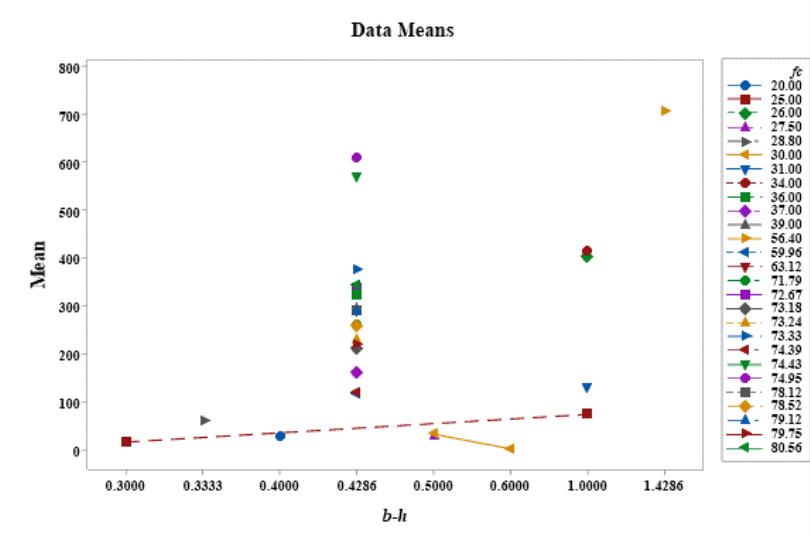

h) Width to depth ratio

Figure 7. The interaction plot between $f_{c}^{\prime}$ and other parameters for the fitted response $(E A)$ 


\subsection{Screening Analysis}

When choosing the essential input variables, one of the key steps is a screening analysis. It is an effective tool to assess each predictor variable's contribution with respect to the response of EA. For this purpose, in this paper, a screening analysis was executed using the design of experiment $(D O E)$ software. Then, the obtained results were presented with the help of the standardized (Figure 8), and Pareto charts (Figure 9). In these figures, the parameters with the most important effects upon the energy absorption (EA) value are presented by order of significance. As can be observed, the EA capacity of the torsional FRP-strengthened RC beams is most significantly affected by the compressive strength of the concrete. The most important parameters that affected the $E A$ are presented by order in Figure 8. This figure shows that the $E A$ value is affected first by the concrete compressive strength, then by the angle of twist, ultimate torque, ultimate FRP strength, and vertical reinforcement ratio, in that order. On the basis of the datasets collected for the purpose of this research, Figure 9 shows that the concrete compressive strength, vertical steel ratio, and FRP thickness, together account for $20 \%$ of the parameters affecting EA. This hypothesis is supported by numerous evidence in the literature [6]. The other parameters, which amount to the remaining $80 \%$ of the Pareto diagram, are comparatively less effective upon EA. In addition, the most important effect plot of the parameters tested in the current paper is illustrated in Figure 10. By definition, the influence of a parameter refers to the change in response induced by a change in the level of said parameter.

The main effect refers to the major parameters of interest in the measured data. A remarkable agreement can be observed between those plots in which the concrete compressive strength significantly affects the $E A$, followed by steel reinforcement ratio, and the thickness of the FRP material. The performance of the effective parameters mentioned in this research is along the same lines of what was found in the literature by the researchers of the torsional FRP-RC beams [15]. Many studies have confirmed that any increase in the $f^{\prime} c$, shear reinforcement ratio of FRP thickness leads to increase in the ultimate torque, resulting in escalating the dissipated energy from the tested beams $[15,39]$. There is an agreement between these findings and the latest studies conducted on the experimental result of torsional behaviour of RC beams wrapped with FRP material, which proves that the ultimate loads, angle of twist, and fully wrapped RC beam gives more torsional strength as compared to reference beam [6].

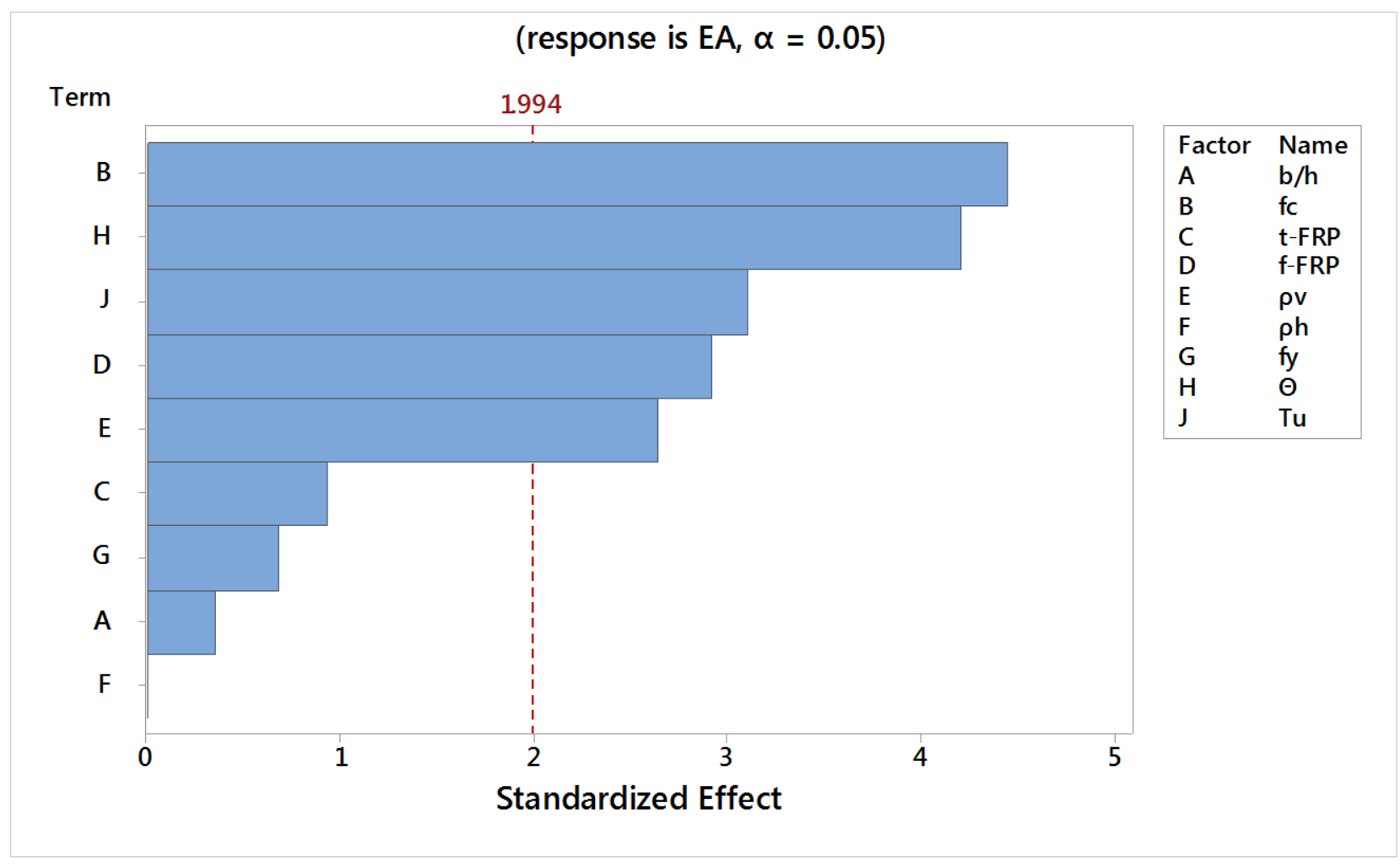

Figure 8. The results obtained from the screening analysis conducted on the proposed model 


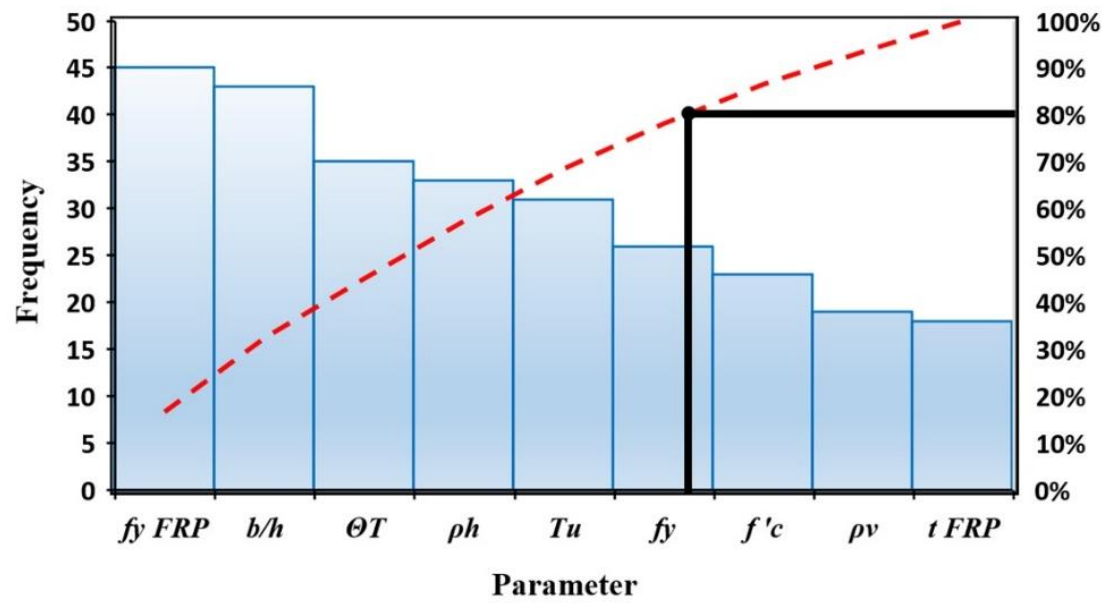

Figure 9. Pareto Chart

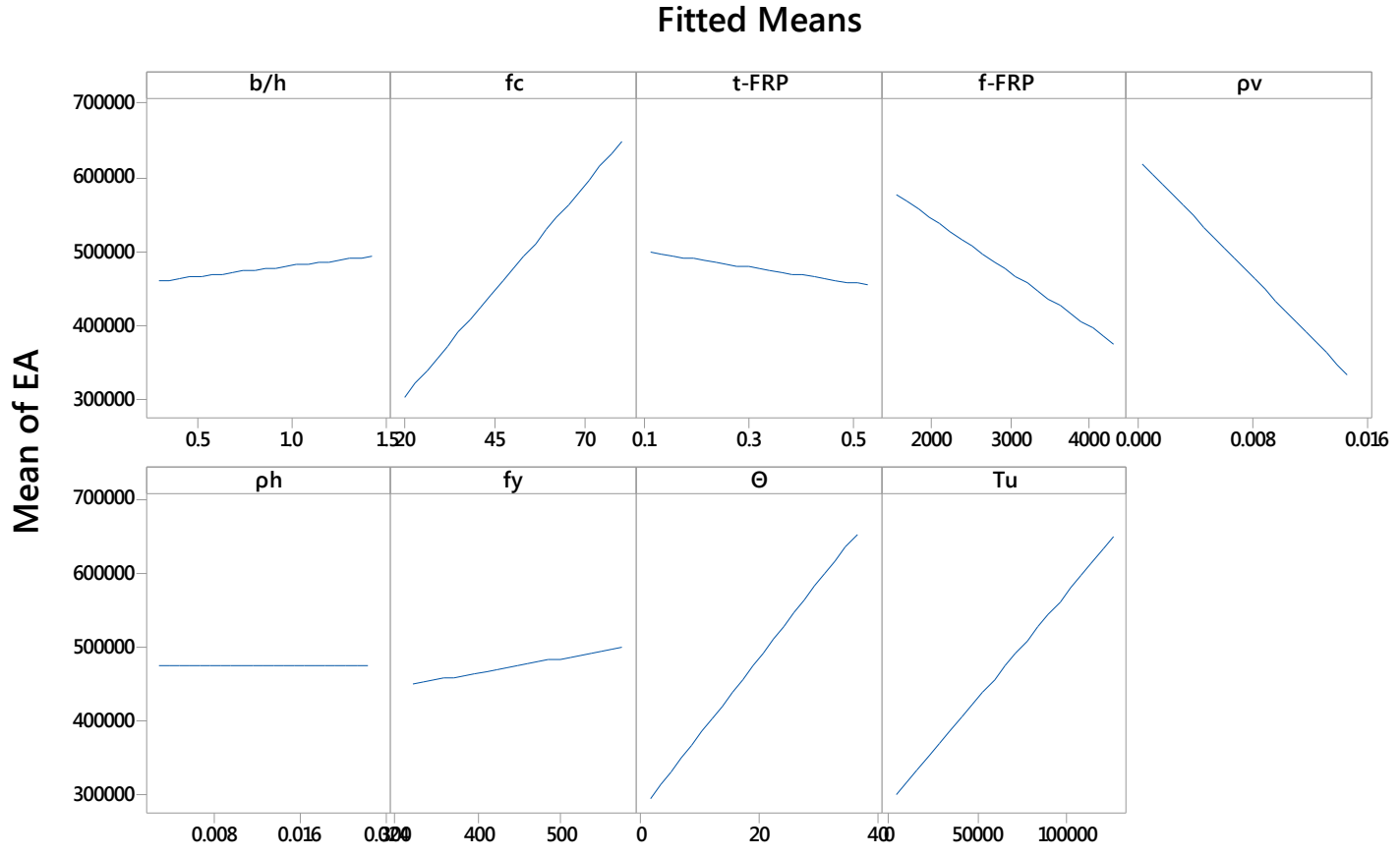

Figure 10. The main effects plot for the energy absorption capacity

\subsection{Modelling of Energy Absorption}

The response surface methodology was implemented to model the responses with the aim of capturing the above behaviour. This study used 81 datasets to construct the model. To provide model acceptability, a minimum ratio of the number of datasets to the number of input variables is recommended, which equals 3 . In addition, it is generally recommended that this ratio exceeds the value of 5 for more safety [40]. To build the proposed model in the current study, this ratio was set to $81 / 5=16.2$. Therefore, the building dataset was higher than the proposed ratio (i.e., 5). The Equation 3 expresses the model result for energy absorption (EA) with regard to the process variables along with the goodness of fit. The quadratic terms, linear effects, and interaction (which were defined earlier in this paper) were obtained using the proposed model.

$$
\begin{aligned}
E A=82675+ & 29375\left(\frac{b}{h}\right)+573 f^{\prime}{ }_{c}-104936 t_{F R P}-73.2 f_{y F R P}-19569252 \rho_{v}-14302 \rho_{h}+196 f_{y} \\
& +10284 \theta_{u}+2.865 T_{u}
\end{aligned}
$$

After construction of the model, its statistical reliability needs to be assessed. Statistically, for the reliability of a model to be well approved, one condition is needed to be met by the model in hand, i.e., the normalized residuals. 'Residual' refers to the difference between a value determined experimentally and the value determined by the model. 
Figure 11 depicts the Minitab outcomes obtained from the nonlinear regression analyses carried out on the energy absorption capacity of RC beams strengthened with FRP, which are exposed to torsional loading impact.

The residual plots display that the deviations between the predicted values and the measured ones are normally distributed, with a few outliers. These plots confirm the efficiency of the proposed model of the energy absorption capacity. The condition defined for model reliability was completely met by the model. According to the logical hypothesis [41], in case the correlation coefficient $(\mathrm{R})$ of a model is greater than 0.8 , it shows that the predicted and the actual energy absorption values are strongly correlated. Based on the data presented in Figure 12, it is clear that the model proposed in this paper has an acceptable R-value (0.80) and high accuracy in the predicted target values. Figure 13 presents the line fit plot of the energy absorption capacity with different parameters. In addition, the line fit plots are employed in this study for the purpose of examining whether the proposed model fits the collected datasets, and also whether it satisfies the objective of the research.
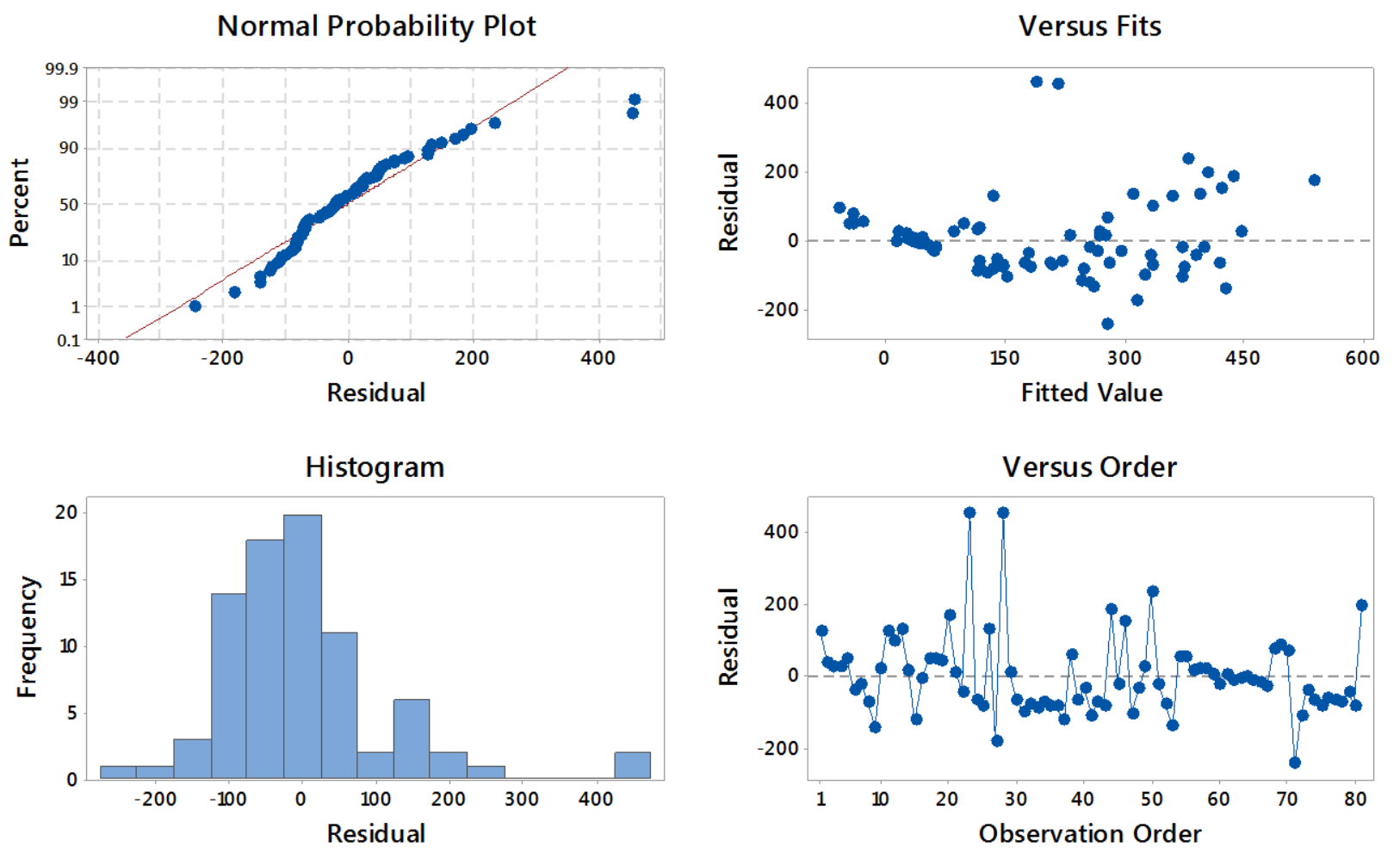

Figure 11. Residual Minitab output of $E A$ capacity

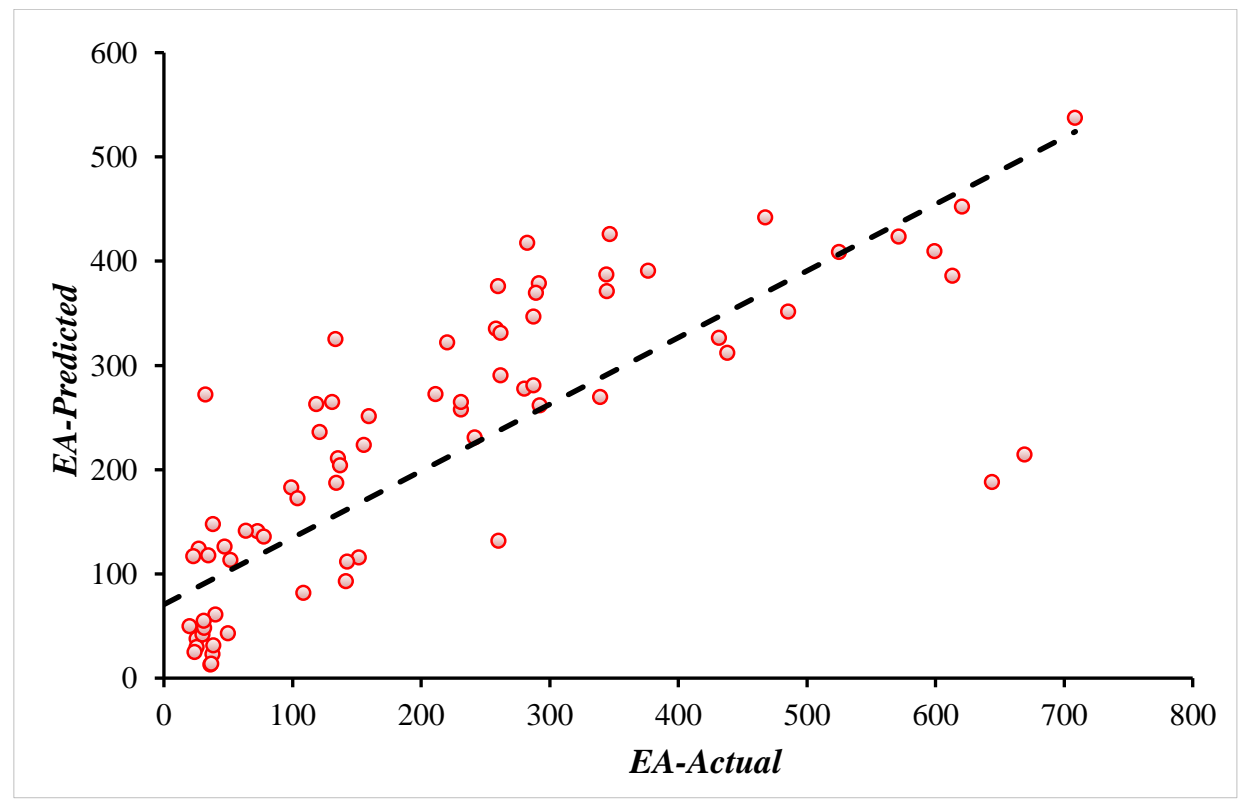

Figure 12. Predicted vs. actual EA capacity using the proposed model 


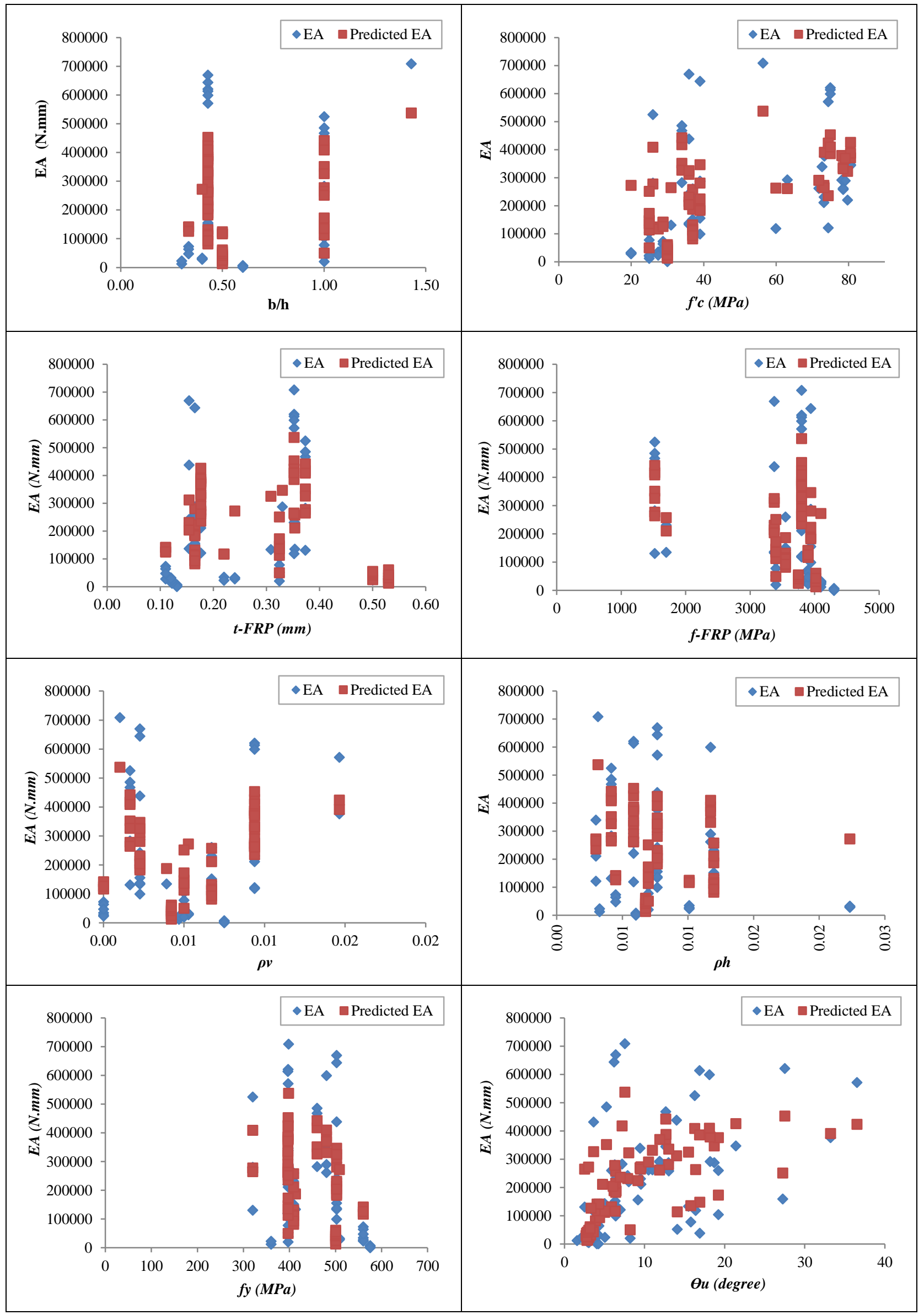




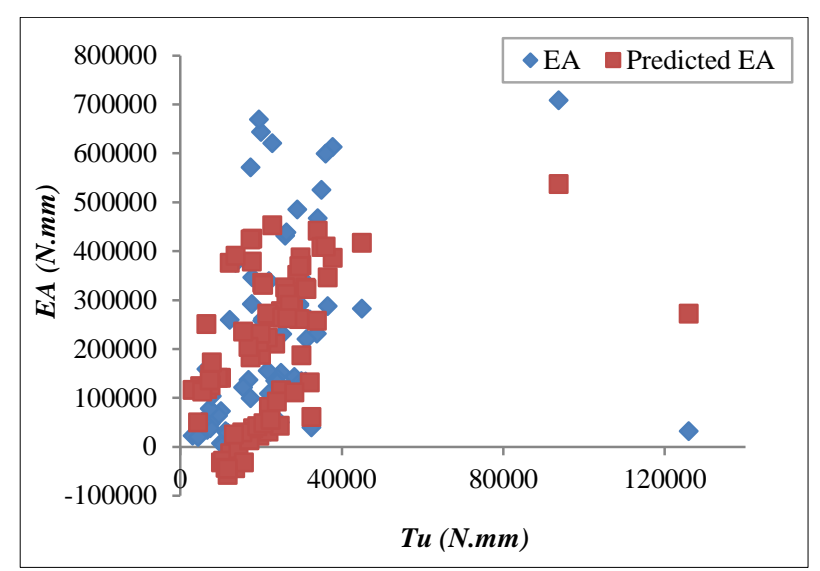

Figure 13. Line fit plot of $E A$ with the independent variables

\section{Conclusion}

The present study is considered the first attempt to investigate the effects of a number of individual parameters (compressive strength $\left[f^{\prime} c\right]$, steel yield strength $[f y]$, FRP thickness [t-FRP], width-to-depth of the beam section $[\mathrm{b} / \mathrm{h}]$, horizontal $[\rho h]$ and vertical $[\rho v]$ steel ratio, angle of twist $[\theta u]$, ultimate torque $[T u]$, and FRP ultimate strength $[(f y-$ $F R P]$ ) upon the energy absorption (EA) capacity of torsional RC beams strengthened by means of FRP sheets. This work is limited to the properties of the eighty-one specimens obtained from previous scientific literature, as far as known by the researcher of this study, to determine the high and low influences of various parameters on the energy absorption of the torsional FRP-RC beams featured in this study, using response surface methodology (RSM). Investigation of the most impactful variables on the torsional absorbed energy of FRP-RC beams will hopefully contribute to future scientific studies by providing knowledge on factors which have major effects on the energy released by the torsional FRP-RC members. Besides, eliminating the non-effective parametric factors from the conducted study leads to reduction in cost, time and efforts. The datasets formed in this study are applicable to the construction of an innovative model capable of effectively predicting the energy absorption capacity.

The RSM technique is effectively applicable to the determination of the energy absorption, as well as a number of engineering problems. It is capable of providing optimum results with an acceptable degree of accuracy when predicting the energy absorption values in consideration with different parameters. The results show that $20 \%$ of the parameters affecting the EA value are the concrete compressive strength, FRP thickness and vertical steel ratio. The rest of the parameters have a lower impact upon EA, and represent $80 \%$ of the Pareto diagram. According to the standardized screening analysis determination, the most important factor is the concrete compressive strength, followed by other four parameters of the angle of twist, ultimate torque, ultimate FRP strength, and vertical reinforcement ratio. An agreement was found between the standardized plot and the Pareto chart of the most effective parameters upon the EA value, i.e., the compressive strength and vertical steel ratio. The model proposed in this paper has shown a sufficient correlation coefficient (R) (i.e., 0.80 ), and the target values estimated with the proposed model were of an acceptable level of accuracy for civil engineering applications. In cases where the energy absorption capacity is calculated with the use of the model proposed in this paper, the structural safety under serious loads may be computed by comparing the applied external energy exerted by the loadings, to the energy absorption capacity of the members. Information that could be used to estimate the energy absorption is rare. Therefore, for future researches, further data is required to be collected for the examination and development of a model for prediction of energy absorption and also for the analysis of a wider range of parameters.

\section{Acknowledgements}

The authors gratefully acknowledge the support for the research provided by the University of Baghdad and the Universiti Kebangsaan Malaysia (UKM).

\section{Conflicts of Interest}

The authors declare no conflict of interest.

\section{References}

[1] Mahir Mahmod, H., A. A. Farah Nora Aznieta, and Sarah Jabbar Gatea. "Evaluation of Rubberized Fibre Mortar Exposed to Elevated Temperature Using Destructive and Non-Destructive Testing." KSCE Journal of Civil Engineering 21, no. 4 (August 19, 2016): 1347-1358. doi:10.1007/s12205-016-0721-0. 
[2] Mahmod, Mahir, Ammar N. Hanoon, and Haitham J. Abed. "Flexural Behavior of Self-Compacting Concrete Beams Strengthened with Steel Fiber Reinforcement." Journal of Building Engineering 16 (March 2018): $228-237$. doi:10.1016/j.jobe.2018.01.006.

[3] Sardar, Sardasht, Mahir Mahmod, and Imad Shakir. "Nonlinear Pushover Analysis for Steel Beam-Column Connection." Eurasian Journal of Science and Engineering 3, no. 1 (2017): 83-98. doi:10.23918/eajse.v3i1sip83.

[4] Jabbar, Sarah, Farzad Hejazi, and H. Mahir Mahmod. "Effect of an Opening on Reinforced Concrete Hollow Beam Web under Torsional, Flexural, and Cyclic Loadings." Latin American Journal of Solids and Structures 13, no. 8 (August 2016): 15761595. doi:10.1590/1679-782512629.

[5] Burciaga, Ulises Mercado. "Sustainability Assessment in Housing Building Organizations for the Design of Strategies against Climate Change.” HighTech and Innovation Journal 1, no. 4 (December 1, 2020): 136-147. doi:10.28991/hij-2020-01-04-01.

[6] Kandekar, Sachin B., and Rajshekhar S. Talikoti. "Torsional Behaviour of Reinforced Concrete Beam Wrapped with Aramid Fiber." Journal of King Saud University - Engineering Sciences 31, no. 4 (October 2019): $340-344$. doi:10.1016/j.jksues.2018.02.001.

[7] Chen, Hui, Wei-Jian Yi, Zhongguo John Ma, and Hyeon-Jong Hwang. "Modeling of Shear Mechanisms and Strength of Concrete Deep Beams Reinforced with FRP Bars." Composite Structures 234 (February 2020): 111715. doi:10.1016/j.compstruct.2019.111715.

[8] Hanoon, Ammar N., M.S. Jaafar, Salah R. Al Zaidee, Farzad Hejazi, and F.N.A. Abd Aziz. "Effectiveness Factor of the Strutand-Tie Model for Reinforced Concrete Deep Beams Strengthened with CFRP Sheet.” Journal of Building Engineering 12 (July 2017): 8-16. doi:10.1016/j.jobe.2017.05.001.

[9] Hanoon, Ammar N., M. S. Jaafar, Farzad Hejazi, and Farah N.A. Abdul Aziz. "Energy Absorption Evaluation of Reinforced Concrete Beams Under Various Loading Rates Based on Particle Swarm Optimization Technique.” Engineering Optimization 49, no. 9 (December 1, 2016): 1483-1501. doi:10.1080/0305215x.2016.1256729.

[10] Song, Zhibo, Shizhao Ming, Tong Li, Kaifan Du, Caihua Zhou, and Bo Wang. "Improving the Energy Absorption Capacity of Square CFRP Tubes with Cutout by Introducing Chamfer.” International Journal of Mechanical Sciences 189 (January 2021): 105994. doi:10.1016/j.ijmecsci.2020.105994.

[11] Ameli, Mehran, Hamid R. Ronagh, and Peter F. Dux. "Behavior of FRP strengthened reinforced concrete beams under torsion." Journal of Composites for Construction 11, no. 2 (2007): 192-200. doi:10.1061/(ASCE)1090-0268(2007)11:2(192).

[12] Hii, Adrian KY, and Riadh Al-Mahaidi. "Torsional capacity of CFRP strengthened reinforced concrete beams." Journal of Composites for Construction 11, no. 1 (2007): 71-80. doi:10.1061/(ASCE)1090-0268(2007)11:1(71).

[13] Hii, Adrian K.Y., and Riadh Al-Mahaidi. "An Experimental and Numerical Investigation on Torsional Strengthening of Solid and Box-Section RC Beams Using CFRP Laminates." Composite Structures 75, no. 1-4 (September 2006): $213-221$. doi:10.1016/j.compstruct.2006.04.050.

[14] Abdulhameed, Ali A., and AbdulMuttalib I. Said. "Experimental Investigation of the Behavior of Self-Form Segmental Concrete Masonry Arches.” Fibers 7, no. 7 (July 2, 2019): 58. doi:10.3390/fib7070058.

[15] Alabdulhady, Meyyada Y., and Lesley H. Sneed. "Torsional Strengthening of Reinforced Concrete Beams with Externally Bonded Composites: A State of the Art Review." Construction and Building Materials 205 (April 2019): 148-163. doi:10.1016/j.conbuildmat.2019.01.163.

[16] Zhang, Junyuan, Danfeng Zheng, Bingquan Lu, and Tianqi Zhang. "Energy Absorption Performance of Hybrid Cross Section Tubes Under Oblique Loads.” Thin-Walled Structures (November 2020): 107133. doi:10.1016/j.tws.2020.107133.

[17] Kavussi, A., M. Qorbani, A. Khodaii, and H.F. Haghshenas. "Moisture Susceptibility of Warm Mix Asphalt: A Statistical Analysis of the Laboratory Testing Results." Construction and Building Materials 52 (February 2014): 511-517. doi:10.1016/j.conbuildmat.2013.10.073.

[18] De Oliveira, Lucas Guedes, Anderson Paulo de Paiva, Pedro Paulo Balestrassi, João Roberto Ferreira, Sebastião Carlos da Costa, and Paulo Henrique da Silva Campos. "Response Surface Methodology for Advanced Manufacturing Technology Optimization: Theoretical Fundamentals, Practical Guidelines, and Survey Literature Review." The International Journal of Advanced Manufacturing Technology 104, no. 5-8 (June 18, 2019): 1785-1837. doi:10.1007/s00170-019-03809-9.

[19] Ghobarah, A., M. N. Ghorbel, and S. E. Chidiac. "Upgrading torsional resistance of reinforced concrete beams using fiberreinforced polymer." Journal of composites for construction 6, no. 4 (2002): 257-263. doi:10.1061/(ASCE)10900268(2002)6:4(257).

[20] Panchacharam, Saravanan, and Abdeldjelil Belarbi. "Torsional behaviour of reinforced concrete beams strengthened with FRP composites. In First FIB Congress, Osaka, Japan. (2002): 01-110. 
[21] Jaafar, Khalaf Ibrahem Mohammad Dr Bayar. "Torsional strengthening of RC beams with CFRP wrap." Tikrit Journal of Engineering Sciences 20, no. 3 (2013): 1-9.

[22] Hii, Adrian KY, and Riadh Al-Mahaidi. "Experimental investigation on torsional behavior of solid and box-section RC beams strengthened with CFRP using photogrammetry." Journal of Composites for Construction 10, no. 4 (2006): 321-329. doi:10.1061/(ASCE)1090-0268(2006)10:4(321).

[23] Al-Mahaidi, Riadh, and Adrian K.Y. Hii. "Bond Behaviour of CFRP Reinforcement for Torsional Strengthening of Solid and Box-Section RC Beams." Composites Part B: Engineering 38, no. 5-6 (July 2007): 720-731. doi:10.1016/j.compositesb.2006.06.018.

[24] Chalioris, Constantin E. "Torsional Strengthening of Rectangular and Flanged Beams Using Carbon Fibre-ReinforcedPolymers - Experimental Study." Construction and Building Materials 22, no. 1 (January 2008): 21-29. doi:10.1016/j.conbuildmat.2006.09.003.

[25] Mohammadizadeh, Mohammad Reza, MJ Fadaei, and HR Rounagh. "Improving torsional behaviour of reinforced concrete beams strengthened with carbon fibre reinforced polymer composite." (2009): 315-327.

[26] Mohammadizadeh, M.R., Fadaee, M.J., "Experimental investigation on torsional strengthening of high-strength concrete beams using CFRP sheets.” Kuwait J Scien Eng, (2009). 36.

[27] Elwan, S. K. "Torsion Strengthening of RC Beams Using CFRP (parametric Study).” KSCE Journal of Civil Engineering 21, no. 4 (August 30, 2016): 1273-1281. doi:10.1007/s12205-016-0156-7.

[28] Tibhe, Shraddha B., and Vijaykumar R. Rathi. "Comparative Experimental Study on Torsional Behavior of RC Beam Using CFRP and GFRP Fabric Wrapping.” Procedia Technology 24 (2016): 140-147. doi:10.1016/j.protcy.2016.05.020.

[29] Al-Bayati, G, R. Al-Mahaidi, and R. Kalfat. "Torsional Strengthening of Reinforced Concrete Beams Using Different Configurations of NSM FRP with Epoxy Resins and Cement-Based Adhesives." Composite Structures 168 (May 2017): 569581. doi:10.1016/j.compstruct.2016.12.045.

[30] Jariwala, Vishnu H., Paresh V. Patel, and Sharadkumar P. Purohit. "Strengthening of RC Beams Subjected to Combined Torsion and Bending with GFRP Composites.” Procedia Engineering 51 (2013): 282-289. doi:10.1016/j.proeng.2013.01.038.

[31] Mohammadizadeh, M. R., and MJ Fadaei. "Torsional behavior of high-strength concrete beams strengthened using CFRP sheets; an experimental and analytical study." (2009): 321-330.

[32] Grace, Nabil F., A. K. Soliman, G. Abdel-Sayed, and K. R. Saleh. "Behavior and ductility of simple and continuous FRP reinforced beams." Journal of composites for construction 2, no. 4 (1998): 186-194. doi:10.1061/(ASCE)10900268(1998)2:4(186).

[33] Fujikake, Kazunori, Tomonori Ohno, and Takashi Nishioka. "Experimental Study on Energy Absorption Capacity of Reinforced Concrete Frames.” Doboku Gakkai Ronbunshu no. 390 (1988): 113-121. doi:10.2208/jscej.1988.390_113.

[34] Nielsen, M.P., Hoang, L.C., Limit analysis and concrete plasticity. (2016): CRC Press.

[35] Godat, A., Z. Qu, X. Z. Lu, P. Labossière, L. P. Ye, and K. W. Neale. "Size Effects for Reinforced Concrete Beams Strengthened in Shear with CFRP Strips.” Journal of Composites for Construction 14, no. 3 (June 2010): $260-271$. doi:10.1061/(asce)cc.1943-5614.0000072.

[36] Box, G.E., Draper, N.R., Empirical model-building and response surfaces. (1987): John Wiley \& Sons.

[37] Myers, R., “Response Surface Methodology, Edwards Brothers Inc.” Distributors Ann Arbor, Michigan, USA, (1976).

[38] Antony, J., Design of experiments for engineers and scientists. (2014): Elsevier.

[39] Hanoon, Ammar N., Ali A. Abdulhameed, Haider A. Abdulhameed, and Saad K. Mohaisen. "Energy Absorption Evaluation of CFRP-Strengthened Two-Spans Reinforced Concrete Beams under Pure Torsion.” Civil Engineering Journal 5, no. 9 (September 23, 2019): 2007-2018. doi:10.28991/cej-2019-03091389.

[40] Davies, A. M. C. "The Data Analysis Handbook, I. E. Frank and R. Todeschini, Elsevier, Amsterdam, 1994, ISBN-444-816593,386 Pp., Dfl325, US\$185.” Journal of Chemometrics 9, no. 5 (September 1995): 431-432. doi:10.1002/cem.1180090509.

[41] Smith, G.N., "Probability and statistics in civil engineering." Collins professional and technical books, (1986). 244. 